\title{
Influence of parallel evolving microstructure on thermal diffusivity in strontium titanate
}

\begin{abstract}
This paper reports some research findings on the parallel evolutions of microstructural properties and thermal diffusivity in strontium titanate. Strontium titanate samples have been prepared via the high energy ball milling technique and subsequently moulded by a hydraulic pressing and followed by cold isostatic pressing. Nanometer-sized compacted powder samples were sintered from 500 to $1400^{\circ} \mathrm{C}$ using $100^{\circ} \mathrm{C}$ increments. Strontium titanate formation was observed at as early as $500^{\circ} \mathrm{C}$ sintering temperature alongside secondary phases. The full formation of strontium titanate was observed at $800^{\circ} \mathrm{C}$ sintering temperature and above. Average grain sizes showed a fluctuating trend with increased sintering temperatures due to carbonate decomposition at lower sintering temperatures $\left(500\right.$ to $800^{\circ} \mathrm{C}$ ) and grain growth phenomenon at higher sintering temperatures $\left(900\right.$ to $\left.1400^{\circ} \mathrm{C}\right)$. Parallel characterization of evolving thermal diffusivity showed the same trend of fluctuation at low sintering temperatures as indirect relationship but increased with increased grain size due to a lesser amount of phonon scattering. However, thermal diffusivity values decreased with increased temperatures because of increased phonon-phonon scattering.
\end{abstract}

Keyword: Evolution; Microstructure; Nanosized grains; Strontium titanate; Thermal diffusivity 